\title{
Hand Injuries Sustained During Jungle Training
}

\author{
Major B R Singer FRCS, RAMC \\ Specialist in Surgery \\ British Military Hospital Munster, BFPO 17
}

SUMMARY: During the initial six week period of deployment and jungle training in Belize, a 634 man strong infantrys battalion group sustained twenty-three machete hand injuries. Eighteen were treated at battalion level, while fivē required hospital treatment. The management of these injuries is considered.

\section{Introduction}

In Belize an infantry battalion group is deployed essentially between four locations, two in the north and two in the south. The medical support consists of the Force (Senior) Medical Officer, based in the north at the Force Hospital, and the Regimental Medical Officer, based in the south, assisted by regimental medical assistants. Second line support is provided by a field surgical team based at the 15 bed hospital.

The treatment of complex injuries such as hand injuries must be limited to appropriate "emergency" surgery followed by early casualty evacuation to the United Kingdom for further treatment and rehabilitation.

When an infantry battalion group deploys to Belize the troops are rotated through Jungle School to learn jungle warfare skills. The use of the machete features predominantly in the art of movement through the often dense jungle and in shelter erection.

During the initial 6 week period of deployment 23 machete wounds to the hands were sustained, 18 were treated at unit level while 5 cases required hospital treatment. These last cases are examined in detail.

\section{Case 1}

A drummer sustained a laceration to his non dominant index finger when the machete "bounced" off a branch and struck his hand while it was supporting the branch. $\mathrm{He}$ arrived at hospital within 8 hours and a primary repair of a divided extensor tendon was performed.

\section{Case 2}

A guardsman sustained a laceration of his dominant thumb web when his hand slipped down the blade whilst attempting to resheath the machete. His injury was 16 hours old before he presented to the surgical team. The wound was contaminated and he had divided the digital nerves and flexor pollicis longus tendon. Delayed primary suture was performed following initial wound toilet. He was subsequently evacuated for definitive treatment.

\section{Case 3}

A guardsman sustained a laceration to his non dominant index and middle fingers whilst attempting to open a tin with his machete. The injury was intitially thought to involve skin only and primary closure wases performed at unit level. It later became clear that thedigital nerve on the radial side of both fingers and both flexor digitorum profundi tendons were severed. He was $\vec{\omega}$ referred for surgical opinion at which time the skino wounds were well healed and he was then evacuated to the United Kingdom for further treatment.

\section{Case $4 \& 5$}

A guardsman sustained a laceration over the radial styloid of his non dominant wrist, when his macheqe bounced out of control. The wound was closed primarily. It was only the next day that he was referred? to the surgeon when sensory loss secondary to division-

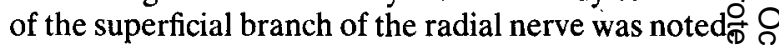

No further treatment was required until 6 weeks latiro when the same soldier sustained a laceration of his nonष dominant thumb in a similar incident. Fortunately this occasion no vital structures were damaged.

\section{Discussion}

The management of hand injuries requires comment on several aspects. At the initial assessment, it is crucialo to recognise the extent of the injuries sustained ${ }^{1}$. This accurate diagnosis allows early surgical intervention, the $\underset{\complement}{\mathbb{Q}}$ value of which was shown in centres employing $\Rightarrow$ techniques which appeared to be in contravention of 3 traditional principles ${ }^{2,3}$. Advocating primary repair Kleinert ${ }^{3}$ recommended a technique of apposing the severed tendon ends with a single crisscross suture. The repair is protected for the first three weeks by means of a rubber band passed through the tip of the nail and@ attached to the front of a volar plaster of paris slab. Movement is permitted immediately postoperatively, with the elastic band providing support to the repaired tendon. At six weeks all support is removed and active exercises commenced. This technique decreases the incidence of adhesion formation of the flexor tendonso within the tendon sheath and gives superior functional results.

The treatment of these often contaminated wounds requires prompt referral to hospital. Unfortunately, casualty evacuation from the jungle, often at night, mayn be a protracted affair despite the efforts of all involved.In contaminated wounds, following conventional 0 \section{.}


surgical practice, the tendon lacerations are initially ignored and attention is directed towards the skin and soft tissues. Following appropriate wound toilet and delayed primary suture of the skin wound a delayed primary suture of the severed tendons may be performed, usually at about three weeks. All cases received antibiotic therapy (penicillin and flucloxacillin) and tetanus prophylaxis.

Clearly the best results are obtained by preventing the injuries. The majority of machete injuries were sustained in one of two ways. Firstly whilst attempting to chop a thin and elastic branch the non dominant hand is used to steady the branch. The hand is then in danger if the machete, which is often slightly blunted, fails to cut cleanly and bounces instead. The second common injury occurs when attempting to resheath the machete.

An awareness of the problems encountered in the use of the machete will increase the respect for this useful tool and reduce the incidence of machete injuries in future operations.

\section{REFERENCES}

1. MACNICOL M F and LAMB D W, Basic Care of the Injured Hand. :Churchill Livingstone, Edingburgh, 1984.

2. VERDEN C E, Half a century of flexor tendon surgery. $J$ Bone Joint Surg. 1972; 54A: 472-91.

3. KLEINERT H E et al. Primary repair of the flexor tendons. Orthop Clin North Am 1973; 4: 865-76. 